\title{
EL PAISAJE LINGÜÍSTICO NAHUA EN SANTA ANA TLACOTENCO, CIUDAD DE MÉXICO: EL EJERCICIO DE UN DERECHO INDÍGENA
}

\author{
THE NAHUA LINGUISTIC LANDSCAPE IN SANTA ANA TLACOTENCO, \\ MEXICO CITY:THE EXERCISE OF AN INDIGENOUS RIGHT
}

\author{
RIMAYKUNAQ KJAWANA NAHUA SANTA ANA TLACOTENCO, \\ MEXICO JATUN LLAQTAPI: QESWA RUNAQ JUJ ALLANKAYNIN ${ }^{(1)}$
}

\author{
Elsa Del Valle Núñez ${ }^{(2)}$ \\ Universidad Nacional Autónoma de México UNAM, México. \\ Universidad Mayor de San Simón, Bolivia.
}

\begin{abstract}
Resumen: Este artículo presenta una experiencia familiar y comunitaria sobre la elaboración de un paisaje lingüístico en náhuatl en la Comunidad de Santa Ana Tlacotenco, Milpa Alta, en la Ciudad de México, como una estrategia de revitalización.

Describe la situación sociolingüística del náhuatl en la Comunidad de estudio, hace énfasis en algunas de las causas de su pérdida y desplazamiento lingüístico. Posteriormente, sitúa al paisaje como una estrategia de revitalización lingüística y como uno de los derechos lingüísticos indígenas mexicanos que establece la legislación.
\end{abstract}

Palabras clave: Paisaje lingüístico, revitalización, náhuatl, derechos indígenas, política lingüística comunitaria

Abstract: This article presents a family and community experience on the elaboration of a linguistic landscape in Nahuatl in the community of Santa Ana

(1) Traducción: Adrian T. Valer Delgado (Lengua Quechua. Cusco/Qollao)

(2) Licenciada en Derecho, por la Universidad Nacional Autónoma de México UNAM, Magister en sociolingüista, PROEIB Andes, actualmente estudiante de Doctorado en Estudios Socioculturales, Posgrado de la Facultad de Humanidades y Ciencias de la Educación, de la Universidad Mayor de San Simón, Bolivia, Cochabamba. Hablante de la lengua náhuatl, variante del centro de México. Correo electrónico: sarahine@hotmail.com; elsadelvallen@gmail.com 
Tlacotenco, Milpa Alta, in Mexico City, as a revitalization strategy. Describes the sociolinguistic situation of Nahuatl in the study community, emphasizes some of the causes of its loss and linguistic displacement. Subsequently, it places the landscape as a linguistic revitalization strategy and as one of the indigenous Mexican linguistic rights established by law.

Key words: Linguistic landscape, revival, Nahuatl, indigenous rights, community language policy.

Ñujñu: Kay qelqaqa churanmi juj aylluq ruwayninmanta jinaspapas jatun aylluqtawan rimaykunaq qawanamanta náhuatlpi Santa Ana Tlacotenco, Milpa Alta, México Jatun llaqtapi, jujmanta kawsaynimpaq. Kjaway qelqantaqmi ayllurimay náhuatlmanta chay aylluq yachanapi, astawantaqmi ruwan chinkaynimpaq kasqanmanta jinaspapas juj llaqtakunaman rimaykunaq ripuyninta. Kjepatataq churan kjawanata juj jujmanta rimaykunaq kawsayninta jinaspapas juj qeswa runaq mexicumanta rimaykuna allankayninmanta camachicuycuna churasqanmanta.

Kichana rimaykuna: Paisaje lingüístico, revitalización, náhuatl, derechos indígenas, política lingüística comunitaria 


\section{Introducción}

Este artículo académico está sustentado en el trabajo etnográfico en el pueblo originario de Santa Ana Tlacotenco, desde el año 2017 a la fecha. A través de una suma importante de entrevistas y de diferentes observaciones participantes hemos realizado un estudio sociolingüístico local y, además incidido junto a sus comuneros hablantes de la lengua náhuatl, en la elaboración y colocación de un paisaje lingüístico en su lengua originaria como una estrategia para su revitalización.

El pueblo originario de Santa Ana Tlacotenco se ubica en la Alcaldía de Milpa Alta en la Ciudad de México. Respecto a las lenguas que se hablan en este lugar, el español es la lengua de uso diario; el náhuatl ya poco se habla entre esta población que asciende a más de 10,000 habitantes.

La lengua náhuatl está seriamente en peligro al no existir una transmisión intergeneracional. Los/as niños y los/as jóvenes tienen como primera lengua el español y sólo pocos abuelos y abuelas (de 70 a 90 años o más) y algunos señores o señoras (50 a 60 años) aún la hablan en momentos esporádicos.

Algunos de los abuelos/as nahuahablantes comentan que: "Ya no la hablamos, así como estamos hablando ahorita el español, ahorita ya no la hablamos pues porque ya no hay quiénes nos contesten en náhuatl." (Conv. DJ. 23/11/2019, Tlacotenco). Al no ser los hijos y los nietos hablantes de la lengua náhuatl, los abuelos y las abuelas silencian su lengua originaria por falta de interlocutores en la familia. Así mismo la inexistencia de vecinos, compadres y amigos nahuahablantes deja percibir que por los barrios de Tlacotenco hay muy poca probabilidad de escuchar a la gente conversar en náhuatl. Además, las personas que sí son competentes oralmente en esta lengua, aun cuando se encuentran en un mismo espacio o evento comunicativo de interlocutores nahuahablantes, no la usan, situación que aumenta el proceso de desplazamiento lingüístico, optando por el uso del español tanto en los ámbitos privado y público.

La pérdida de esta lengua, reflexionan los tlacotenses, se debió sobre todo a la práctica lingüística que empezó a generalizarse en este territorio originario a partir de 1940. Algunos de los comuneros tlacotenses comentan que:

"Antes se hablaba mucho, mucho náhuatl, todo era en náhuatl, llegaban los abuelos, las abuelas, los papás y todos hablaban, pero uno de chamaco, de niño, no podía meterse en sus conversaciones, era asunto de gente grande y nos decían, porque estábamos por ahí jugando, medio escuchando: -váyanse para allá; a mí me decía mi papá: -vete para allá; y sí veíamos que ellos hablaban en náhuatl, reían, todo decían en náhuatl, pero a nosotros no nos hablaban así, puro español, ya no nos hablaron el náhuatl" (Ent. JL. 23/02/2017, Tlacotenco). 
Según el anterior testimonio, la lengua náhuatl se comenzó a ver socialmente como una lengua de uso para la gente mayor. Como consecuencia, en la actualidad el uso de la lengua náhuatl en Santa Ana Tlacotenco se reduce a una comunidad de personas de edad avanzada, con dificultades para ser auténticos actores en los procesos de revitalización lingüística, aunque en ellos existe el interés de salvaguardar su lengua.

Es importante decir que en Santa Ana Tlacotenco, como en otras comunidades indígenas nahuas, se irradiaron las creencias etno-lingüísticas de que el "náhuatl es cosa de indios, el náhuatl es antiguo, sí les sigues hablando en náhuatl, tus hijos no serán capaces de aprender el español" (Ent. DJ. 21/01/2018, Tlacotenco). Estas aseveraciones negativas incentivaron el silenciamiento de la lengua náhuatl en esta Comunidad para evitar ser discriminados por su origen étnico y por el uso de su lengua originaria. Un comunero tlacotense, por escrito expresó ¿por qué sus padres no le hablaban en la lengua náhuatl?:

"Les pregunté a mis padres por qué no nos hablaban en náhuatl a nosotros sus hijos a pesar que lo hacían muy bien. Nuestra mamá me contestó que más o menos a los diez años empezó a trabajar con una maestra, una de las hijas de la familia Miranda, quien le había comentado que dejara de hablar náhuatl y aprendiera español porque, de lo contrario, no podría hablar esta lengua. Le metió tanto la idea que a nosotros sus hijos poco nos hablaba en su lengua madre" (Silva, 2008:279).

El rol del maestro y el de la escuela consistía en erradicar las culturas indígenas y sus lenguas a través de políticas educativas asimilacionistas. Al respecto, uno de los comuneros tlacotenses expresó: "Ia lengua náhuatl dejó de transmitirse cuando ingresamos a la escuela y teníamos que prepararnos, ¿sabes qué pasó? Los maestros negaron, les negaron y les prohibieron hablar su lengua a los abuelos" (Conv. JO. 29/01/17, Tlacotenco).

Otro testimonio en referencia a las directrices que tuvo la escuela con relación a la lengua náhuatl en Santa Ana Tlacoteco, refiere que: "a los niños en la escuela ya no les permitían que hablaran en náhuatl, les mandaban a decir los maestros- a su mamá que ya no les enseñen a hablar así, sino, no van a poder aprender el español, eso fue" (Conv. DJ. 27/01/17, Tlacotenco). Según las opiniones de los comuneros tlacotenses hubo una presión del exterior, del ámbito escolar, desde donde se impulsó el silenciamiento de la lengua originaria hacia el ámbito familiar. El comportamiento más inmediato de los padres y abuelos fue callarse y no heredar a sus hijos y nietos la lengua originaria como medio de comunicación en su vida diaria. 
Los padres y abuelos tlacotenses acataron las instrucciones que dispuso la escuela; por ende, contribuyeron "inconscientemente" o "concientemente" en el fortalecimiento de la política nacionalista del Estado mexicano de los años 40 y 50, el cual demandó una cultura, una lengua, favoreciendo el monolingüismo en español. Como alude Sichra (2016), en su estudio (tanto en Bolivia como en México) a modo de coincidencia con el panorama sociolingüístico del náhuatlen Santa Ana Tlacotenco:

Respecto al rol que los abuelos juegan en la transmisión intergeneracional de las lenguas indígenas. Datos sociolingüísticos recabados por algunos tesistas del PROEIB-Andes en familias en poblados y familias migrantes hacia una región urbana en México y Bolivia, revelan políticas lingüisticas que involucran a la generación más adulta impulsando de hecho o asumiendo implícitamente el desplazamiento de lenguas indígenas hacia dentro de sus familias antes que representando un tradicional «nicho lingüístico» favorable al mantenimiento de las lenguas (pág. 135).

En el escenario tlacotense se vivió y se vive la oxidación de la lengua náhuatl por el mismo hábito de los abuelos y de los padres de no hablar la lengua náhuatl con los nietos y los hijos. Por lo tanto coincidimos con Sichra (2014), quien señala que:

"El marco de vulnerabilidad y pérdida, entonces, no se explica por causas naturales, deterioro de células, envejecimiento, proceso de oxidación, por así decirlo, de las lenguas indígenas, es producto de una construcción sociopolítica que los mismos concernidos han asumido como propia y es nutrida por la sociedad hegemónica, el poder social. El deterioro y la pérdida de lenguas se promueven, por así decirlo, "desde adentro" en respuesta a una presión "de afuera". Una manera de deterioro es vía el 'silenciamiento intergeneracional', como lo llaman algunos (Hilario Chi, 2012. p.2)

Bajo este escenario sociolingüístico donde la lengua náhuatl padece los estragos de la diglosia, en una situación en la que dos lenguas se encuentran en una relación de dominación/subordinación, la lengua originaria tiene poca posibilidad de subsistencia, ya que el español es la lengua de prestigio y de mercado laboral, económico y educativo; reservándose la lengua indígena a funciones simbólicas como el aprendizaje de cantos y el pronunciamiento de algunos discursos preparados para algún evento político o cultural, acciones que inciden en la revalorización de la identidad nahua, pero estas, no impactan directamente en el uso de la lengua originaria.

Un vistazo a la escala graduada de deterioro intergeneracional para lenguas amenazadas de Fishman (1991), nos permite posicionar a la lengua náhuatl de los tlacotenses en los estadíos 7 y 8 , en los que se muestra un deterioro 
profundo. Según esos estadíos y observando la realidad lingüística tlacotense, la lengua náhuatl es "usada por los mayores y no por la generación joven", y además hay un "aislamiento social de los pocos hablantes que quedan de la lengua minoritaria". Por lo tanto, el náhuatl en Santa Ana Tlacoteco se encuentra en peligro de extincion.

\section{Revitalización idiomática y paisaje lingüístico}

Flores y Córdova (2012) precisan que existe una serie de acciones con el objetivo de lograr que la diversidad lingüística del planeta no desaparezca (publicación de libros, pronunciamiento de leyes, elaboración de currículos escolares, financiación de proyectos, creación de instituciones, entre otros). A esta serie de acciones y a otras similares enfocadas al uso y a la continuación de las lenguas minorizadas y minoritarias en el mundo se las considera estrategias comunes en los procesos de revitalización lingüística.

Para López (2015), la revitalización idiomática consiste en ejecutar acciones que tienen por objetivo reactivar el uso cotidiano de las lenguas vulnerables, amenazadas y en peligro de extinción. Incluye también aquellas que contribuyan a la apropiación y el reaprendizaje de las lenguas, así como también las que cumplen una función simbólica, aunque estén más relacionadas con el fortalecimiento de la identidad de un grupo cultural.

La variedad de acciones en los procesos de revitalización lingüística es tan amplia, como heterogéneos son los actores que las elaboran y las ponen en marcha en los contextos reales. Lingüistas, etnógrafos, historiadores, abogados, antropólogos, médicos, pedagogos, psicólogos, maestros, activistas, músicos, cantantes, el Estado, organizaciones internacionales, los propios hablantes,entre otros, han desplegado acciones encaminadas a dar embate a la constante pérdida de las lenguas en peligro bajo diferentes criterios y enfoques.

El paisaje lingüístico es hoy en día, una más de las acciones implementadas en los procesos de revitalización de lenguas amenazadas. Para efectos de este artículo entendemos el paisaje lingüístico como Landry y Bourhis (1997) lo describen: el lenguaje presente en los letreros de carreteras públicas, carteles publicitarios, nombres de calles, nombres de lugares, letreros de tiendas comerciales y letreros públicos en edificios gubernamentales que hay en un determinado espacio geográfico.

Aunque el estudio de este tema es muy reciente, existen importantes experiencias documentadas sobre este tópico y su relación con la situación sociolingüística en territorios con conflicto de lenguas. Por ejemplo, a nivel mundial son conocidos los casos de Bélgica y de Quebec, donde fue necesario que: "los planificadores de idiomas reconocieran importante marcar los territorios 
lingüísticos a través de la regulación del uso del idioma en las vallas publicitarias, letreros de calles, letreros comerciales, nombres de lugares y otros semejantes (Landry y Bourhis, 1997: 24)

A nivel nacional, en México, el Instituto Nacional de Lenguas Indígenas (INALI), organismo creado para la salvaguarda del patrimonio lingüístico originario, reportó su apoyo el año 2016 a la comunidad de Santa María Ixcatlán, Oaxaca, para la realización de un paisaje lingüístico, el cual consistió en elaborar letreros con los nombres de calles y escuelas, oficinas municipales e iglesias en su lengua ixcateca. En otro comunicado, informó acerca del diseño de 60 letreros en lengua mazahua en espacios cotidianos como tiendas, pequeños comercios, callejones, andadores y calles, en el barrio de Santa Martha del Sur, en la Alcaldía de Coyoacán, en la Ciudad de México, el año 2013.

Existen otros reportes de proyectos comunitarios de paisajes lingüísticos en colaboración con el INALI. Durante el 2016 se llevaron a cabo en las variantes lingüísticas mazahua de oriente y otomí del oeste, en Zitácuaro, Michoacán; en la variante lingüística mexicana de Temixco, en Cuentepec, Temixco, Morelos; en lengua tlahuica, el proyecto señalética tlahuica pjyekakjo, Ocuilan, Estado de México; en lengua matlatzinca, el proyecto Mirando mi cultura, en Temascaltepec, Estado de México; en lengua otomí del centro, en San Marcos Tlazalpa, Estado de México; en lengua chontal de Oaxaca en la comunidad de Santo Domingo Chontecomatlan, Oaxaca; en lengua maya, el proyecto Jats'uts Táan en Maya, Yucatán; en lengua maya, el paisaje lingüístico Tin Kaajal Ku táana maaya en el municipio de Oxkutzcab, Yucatán; en lengua maya el proyecto Rescatando Nuestras Tradiciones de la lengua materna Maya en Mama; en lengua maya el paisaje lingüístico bilingüe en el municipio de Sacalum, Yucatán. Todos estos paisajes lingüísticos bajo la idea de hacer visibles las lenguas indígenas nacionales en los distintos espacios de los pueblos y las comunidades. (INALI, 2017). Así como Landry y Bourhis (1997) lo señalan, el paisaje lingüístico contribuye a la notoriedad de las lenguas en el ámbito público.

En el contexto urbano y periurbano de la Ciudad de México es común encontrar en las vías públicas y en edificios o lugares públicos: señalamientos, letreros, anuncios, posters, carteles, rótulos, publicitarios, entre otros, en alguna lengua, sobre todo los hay en español porque es la lengua franca del lugar. Los hay también en inglés y en chino por ejemplo. Lo que significa que hay interlocutores en esas lenguas, que saben leer y escribir.

Coincidimos con Córdova y Yataco (2019) al caracterizar al paisaje lingüístico como un bien cultural que se produce y se consume. Dicho en palabras de Mendoza (2002:199) a quienes citan estas autoras: "observar al paisaje lingüístico 
como circuito cultural es entenderlo como los procesos de producción del bien cultural, su ciclo origen-trayectoria-destino, así como de las condiciones y circunstancias sociales que lo enmarcan" (pág. 92).

En el escenario de Santa Ana Tlacotenco, además de los letreros en español de tiendas, lugares públicos, anuncios políticos, anuncios culturales, avisos de servicios, propaganda, encontramos también algunos en la lengua náhuatl, sobre todo topónimos, que se han colocado de manera simbólica para recordar cómo se nombraba a esos lugares cuando aún la ciudad no había crecido urbanísticamente y el ambiente ecológico se conservaba. Desde luego, por nomenclatura oficial los nombres de los lugares en el territorio de la investigación corresponden a los nombres que el gobierno ha designado a las calles y avenidas y que pertenecen en su mayoría a nombres de personajes de la historia oficial mexicana y no propiamente a la regional. En este caso, las denominaciones en náhuatl son colocadas de manera simbólica, pero llevan consigo la manifestación de la memoria colectiva, pues los comuneros recuerdan cómo se nombraban en la lengua náhuatl esos lugares, los cuales incluso, además del texto alfabético van acompañados de alguna pictografía o iconografía.

Los textos escritos en la lengua náhuatl y exhibidos públicamente inciden en su difusión en el ámbito público, pero además, como no los hacen saber Landry y Bourhis (1997) impactan en el desarrollo del bilingüismo social en lenguas en contacto. Para nuestro caso de estudio, consideramos que el paisaje lingüístico incide sustancialmente en el aprendizaje de la lengua náhuatl en ámbitos informales como la vía pública.

Sin embargo, el paisaje lingüístico en una lengua u otra, va más allá de su función informativa. Landry y Bourhis (1997) refieren que esta figura comunicativa, además de ser una señal de emisión y recepción de mensajes informativos, contribuye a la visibilidad etnolingüística; en ese sentido, hace que la lengua náhuatl sea notoria en carteles públicos, por lo que visibiliza a la comunidad de hablantes presentes en ese territorio, quienes están generando este bien cultural refieren acerca de la vitalidad de las lenguas, su dinamismo y función social en contextos donde conviven varias culturas. Incluso, nos da indicios de procesos de etno-génesis, es decir, de reapropiación identitaria, cultural y lingüística.

Es importante para el desarrollo de las lenguas originarias no obviar que el paisaje lingüístico ejerce además un rol simbólico, representa una marca del poder de la comunidad lingüística que habita en un específico territorio.

En base en esto último, Córdova y Yataco (2019) señalan que los paisajes lingüísticos latinoamericanos en lenguas indígenas son un sistema representacional de procesos de reivindicación étnica, es decir, se generan en 
situaciones de conflictos de lenguas, donde por lo general hay una lengua que no era o no es consolidada a nivel público porque su comunidad de habla carece de poder y sobre la cual existen ideologías que denigran lo étnico, lo cultural y lo lingüístico. De tal manera que hacer visible a una lengua originaria a través de los paisajes lingüísticos implica reivindicar un lenguaje al que antes no se le era permitido ser expuesto en la esfera pública, por ser el habla de los "indios" o de los "indígenas" y cuya forma de comunicación no les era anteriormente reconocida por el Estado y por el sistema jurídico constitucional.

Ese poder simbólico significa que, en el paisaje lingüístico presente en algún territorio geográfico, puede llegar a evidenciarse si existe o no una desigualdad lingüística oficializada por el sector público o en el sector privado, puesto que, en primera instancia, al observar los letreros oficiales de las instituciones gubernamentales, se puede percibir la lengua hegemónica. Luego, la lengua de mercado, en cuál lengua dominante se está ofertando algún bien o servicio. En los dos ámbitos, el español es la lengua predominante en el contexto explorado. Entonces, el paisaje lingüístico "pasa a ser un tema meramente lingüístico a ser una evidencia del medio ambiente social y política gubernamental en el que los habitantes de una lengua se encuentran" (Córdova y Yataco, 2019: 92).

Por lo tanto, es importante socializar el concepto de paisaje lingüístico en los pueblos y las comunidades indígenas, sobre todo en aquellos lugares donde los comuneros están desarrollando la escritura en su lengua originaria, no sólo porque a través de este trabajo se abre un nuevo dominio de uso cotidiano de las lenguas amenazadas, superando la oralidad, sino porque, además, la notoriedad de las lenguas originarias en los paisajes lingüísticos es capaz de ejercer una marca territorial simbólica que coadyuva a la defensa de los territorios físicos ancestrales, legitimando socialmente su uso como mecanismo de defensa de la tierra original que entraña todo un sistema cultural y constituye además un mecanismo de cuidado y desarrollo de la lengua en los contextos actuales, en los que la escritura se vuelve una estrategia de revitalización idiomática. En el caso de los migrantes a la ciudad, por ejemplo, el paisaje lingüístico en sus lenguas coadyuva a la visibilidad de la diversidad lingüística en sociedades complejas y saturadas donde es difícil de percibirse.

Desde esa mirada, la utilidad del paisaje lingüístico en alguna lengua originaria la comprendemos a partir de lo que Landry y Bourhis (1997) nos dicen: "Emerge del campo de la planificación del lenguaje" (pág. 24), noción que nos interesa destacar aquí. Bajo esta comprensión, el paisaje lingüístico es una estrategia para la revitalización de las lenguas indígenas, siempre y cuando sean las comunidades quienes lo generen y sean ellos los actores principales en el proceso de elaboración y colocación, a fin de que el paisaje lingüístico obtenido tenga validez social y sean 
los mismos hablantes quienes lo legitimen y posibiliten su uso y actualización en la vida diaria.

Entendemos que esta figura significa también, la apertura o el cierre de un límite lingüístico en un territorio geográfico. Como Landry y Bourhis (1997) lo aclaran: "La prevalencia de un idioma específico en los carteles públicos también cumple una función informativa en la medida en que indica que el idioma en las preguntas puede usarse para comunicarse"(3) (pág. 25). Simbólicamente, el paisaje lingüístico nos dice qué lengua puede ser usada en la comunicación, no sólo en la oral, sino también en la escrita. Como bien lo señalan Córdova y Yataco (2019), el paisaje lingüístico como un sistema representacional sintetiza en el plano visual y comunicativo auténticas políticas lingüísticas, algunas "desde arriba", otras desde la comunidad, las cuales llevan consigo ideologías lingüísticas, además también de actitudes lingüísticas, por lo tanto, como estas últimas autoras señalan el paisaje lingüístico es un proceso sociocultural y sociolingüístico complejo, "compuesto por modos de interacción humana, negociación y producción mediada por relaciones de poder, materialización de ideologías lingüísticas existentes en torno a las lenguas indígenas y sus posibilidades de mantenimiento, desarrollo y revitalización, tanto en términos de representación alfabética como iconográfica" (pág, 90).

Por lo tanto, el paisaje lingüístico como una estrategia de revitalización lingüista de alguna lengua indígena es uno de los caminos para contribuir al desarrollo de las lenguas en los contextos modernos actuales, no lo es todo, pero sin duda contribuye. Dicho en palabras de Córdova y Yataco (2019):

"Así, la producción del paisaje lingüístico es un evento relevante para comenzar a reconocer la presencia y valor de la diversidad cultural. Sin embargo, esta producción por sí sola no logrará regular o revertir las relaciones de desigualdad entre los hablantes de lenguas indígenas y la sociedad mayor, mucho menos podrá revitalizar una lengua si esto no se relaciona e inserta junto a los procesos de mayor envergadura" (pág. 91).

\section{Paisaje lingüístico, un derecho indígena}

La regulación del uso de una lengua u otra en el ámbito público también aparece en las leyes mexicanas, como bien dan cuenta de ello Landry y Bourhis (1997), quienes enlistan los diferentes Estados cuyas leyes regulan el uso de las lenguas en la esfera pública, según Leclerc 1994:

Más de 30 países y estados regionales han adoptado leyes que regulan aspectos de su panorama lingüístico. Se han aprobado leyes que regulan

(3) "the prevalence of a specific language on public signs also serves an informational function inasmuch as it indicates that the language in questions can be used to communicate" 
específicamente el idioma de los signos públicos en países como Argelia, Austria, Canadá, Colombia, Estonia, Finlandia, Francia, Indonesia, Italia, México, Noruega, Rusia, España, Suiza y Turquía, estados regionales no soberanos como como Massachussetts, Irlanda del Norte y Québec también han aprobado leyes que regulan el idioma de los signos públicos dentro de sus respectivos territorios. ${ }^{(4)}$ (Leclerc, 1994, citado en Landry y Bourhis, 1997:24)

En el caso de México, la Constitución no regula el uso de las lenguas en contacto en el ámbito público, sino que hace referencia a la prohibición de la discriminación por origen étnico, haciéndose extensiva esta prohibición a la discriminación lingüística. En el Art. 1, párrafo 5 señala: "Queda prohibida toda discriminación motivada por [...] o cualquier otra que atente contra la dignidad humana y tenga por objeto anular o menoscabar los derechos y libertades de las personas" (Constitución Política de los Estados Unidos Mexicanos, 2020).

Adicionalmente en su artículo 2, señala que: "Esta Constitución reconoce y garantiza el derecho de los pueblos y las comunidades indígenas a la libre determinación y, en consecuencia, a la autonomía para: Fracción IV. Preservar y enriquecer sus lenguas, conocimientos y todos los elementos que constituyan su cultura e identidad".

No obstante, es en la Ley General de Derechos Lingüísticos de los Pueblos Indígenas (2003) donde se establece como uno de los derechos lingüísticos de los pueblos y las comunidades indígenas, contar con un paisaje lingüístico, el cual se limita a "señales informativas de nomenclatura oficial, así como que los topónimos sean inscritos en español y en las lenguas originarias", a la letra el artículo 13 establece que:

"Corresponde al Estado en sus distintos órdenes de gobierno la creación de instituciones y la realización de actividades en sus respectivos ámbitos de competencia, para lograr los objetivos generales de la presente Ley, yen particular las siguientes: Fracción XV. Instrumentar las medidas necesarias para que, en los municipios indígenas del país, las señalas informativas de nomenclatura oficial, así como sus topónimos, sean inscritos en español y en las lenguas originarias de uso en el territorio (fracción adicionada en el 2010), (LGDLPI, 2020)"

(4) More than 30 countries and regional states have adopted laws regulating aspects of their linguistic landscape. Laws especifically regulating the language of public signs have been passed in countries such as Algeria, Austria, Canada, Columbia, Estonia, Finland, France, Indonesia, Italy, Mexico, Norway, Russia, Spain, Switzerland, and Turkey, Nonsovereign regional states such as Massachussetts, Northern Ireland, and Québec have also passed laws regulating the language of public signs within their respective territories 
En el artículo citado se hace hincapié en los elementos que constituyen de manera legal al paisaje lingüístico, que se reduce a dos tipos de mensajes escritos: 1) las señales informativas de nomenclatura oficial y 2) los topónimos. En este sentido, consideramos importante que la ley en cuestión, y las relacionadas, amplíen y analicen con mayor profundidad este tema, extendiéndose la regulación jurídica de un paisaje lingüístico al sector privado, en el que los comercios y las empresas coadyuven en la preservación y la difusión de las lenguas indígenas, lo que puede operarse de manera territorial, como se está tratando de hacer con el náhuatl de Santa Ana Tlacotenco, donde se pretende que en el mercado, tiendas y comercios de los comuneros, se les coloque oficialmente el nombre de su negocio en esta variedad lingüística, a efectos de contribuir a su revitalización idiomática.

\section{Política lingüística comunitaria en la elaboración de un paisaje lingüístico en náhuatl en el pueblo de Santa Ana Tlacotenco}

La política lingüística comunitaria nace desde que en los pueblos y las comunidades indígenas han comprendido que los Estados Nación no resuelven el problema de la pérdida acelerada de las lenguas originarias en la actualidad. Queda claro que revertir el desplazamiento lingüístico no es una tarea fácil, sino constituye un proceso sociocultural y sociolingüístico complejo en el que se debe de incidir en diferentes aspectos de la vida cotidiana de los hablantes y no hablantes de estas lenguas.

No obstante, "desde abajo", los actores indígenas cada día aseveran que continuar delegando la tarea del cuidado de las lenguas a los gobiernos hegemónicos ya no asegura el resguardo y la continuación de las lenguas indígenas, aunque existan legislaciones y marcos jurídicos nacionales e internacionales en los que se obligue a los Estados al cumplimiento eficaz del derecho a la lengua.

Desde esta óptica en el pueblo originario de Santa Ana Tlacotenco, hemos acordado realizar un paisaje lingüístico en la lengua náhuatl. Este trabajo es una de la actividades del proyecto comunitario "Aún nuestra lengua vive: fogatas nahuas móviles tradicionales", en el que nos ocupamos además del tema que abordamos en este artículo, la documentación de esta lengua originaria.

Adjetivamos como casero el paisaje lingüístico que elaboramos en esta comunidad, porque: "Este trabajo es de casa, aquí con la familia, los vecinos y los que gusten acompañarnos y ayudarnos a revivir el náhuatl" (Conv. LM. 22/06/2019, Tlacotenco). Esta estrategia de revitalización de la lengua náhuatl, tiene como características: 
1. "Que se hace o cría en casa": Efectivamente, el paisaje de la lengua náhuatl se inicia en el hogar de una pareja de abuelos nahuas, la abuela Damiana Jardines Garibay y su esposo Liborio Meza Patiño quienes tienen 78 años dedicados al trabajo del campo y al comercio del maíz, el nopal, y otros productos agrícolas que cosechan. Estos dos actores nahuas albergan y cobijan en su casa el proyecto familiar y comunitario "Aún nuestra lengua vive: fogatas nahuas móviles tradicionales". Por lo tanto, los actores del paisaje náhuatl son además de estos abuelos, sus hijas, nietos, sobrinos, vecinos de barrio y público en general que desean vivir la experiencia. Hablamos entonces de un grupo familiar y comunitario no especializado.

2. "Que se hace con medios": En este sentido, para efectuar el paisaje lingüístico del náhuatl usamos tablas de madera, pinturas, lazos, algunos aparatos tecnológicos como la cámara fotográfica, la cámara de video, grabadoras y teléfonos celulares; además del uso de una pizarra para el registro de la lengua originaria.

3. "Que se hace entre personas de confianza": Ciertamente esto es válido, pues la dinámica de paisaje que seguimos se hace entre las familias y los vecinos del barrio. Por lo tanto, entre los actores participantes hay una estimación, aprecio, cariño, compromiso, confianza y amor a la lengua originaria.

4. Según el saber popular, sin dificultad o ciencia, aunque eficaz": Hinton (2001) nos sugiere que: "La planeación lingüística es esencial para un buen programa de revitalización"(5) (pág. 51). En base a este comentario, la experiencia del paisaje en náhuatl ha requerido de un planeamiento previo, aunque no muy riguroso, pues se alimenta del trabajo diario y de la creatividad y espontaneidad de los participantes.

El paisaje en la lengua náhuatl tiene varios objetivos. En sentido estricto, el objetivo lingüístico es la elaboración de noventa letreros de comercios en la lengua originaria, entre ellos: mercado, escuela, iglesia, carnicería, frutería, papelería, panadería, acuario, pollería, florería, verdulería, baños, tienda, entre otros similares, para ser colocados en la zona central del poblado donde hay más afluencia de personas. Este trabajo pretende que se visibilice la lengua náhuatl y se empiece a gestar un proceso de aprendizaje de este léxico de manera informal en la vía pública. Asimismo, se espera que el gobierno local comience a difundir esta práctica por todo el territorio tlacotense y la región de la Alcaldía de Milpa Alta que es de raíz histórica nahua.

(5) language planning is essential for a good revitalization. (Traducción propia) 
No obstante, otro de los objetivos, que consideramos el de mayor importancia es visibilizar el papel de los abuelos y las abuelas como actores que usan su lengua náhuatl. A través de esta actividad, los hablantes se reapropian de su lengua originaria y visibilizan el náhuatl ante sus familias y vecinos.

Uno más de los objetivos de esta actividad es visibilizar al hogar como un lugar no formal en el que podemos aprender náhuatl en familia, con vecinos y amigos. Es decir, la casa como una cuna donde se gestan los procesos de planificación del lenguaje para su reapropiación y revitalización idiomática y cultural.

\section{Paisaje lingüístico en náhuatl: su metodología}

Para saber qué escribir en las maderas, fue necesario usar la siguiente metodología, que describe uno de los participantes del proyecto:

"Bueno, se invitó a los hablantes del náhuatl, sobre todo a los abuelitos para que nos acompañaran, yentonces, los quellegamos pues conocimos qué era el paisaje, y decidimos hacerlo, lo difícil era ponernos de acuerdo en cómo escribir, pero bueno, después con el tiempo fuimos avanzando. Como siempre nos reunimos aquí en la casa, vienen abuelitos, personas mayores, los señores, jóvenes, y niños, unos pues no saben nada de náhuatl, otros sí sabemos, otros un poco, pero pues ya aquí nos reunimos, nos sentamos y trabajamos, preguntamos a los que saben náhuatl que como se dice mercado, como lo escucharon de chiquitos, y pues unos dicen 'tianquiztle', otros que 'tianquizco', pues así van saliendo las palabras, las escribimos en el pizarrón, y ahí vemos, preguntamos varias veces para no equivocarnos, sobre todo para decir como aquí se dicen en nuestro pueblo, y pues votamos todos, y ya contentos nos ponemos a pintar en las tablitas el letreo, unos hacen los dibujos, otros las letras, y así vamos, lo importante es decir que aquí estamos presentes con el náhuatl, y pues los pequeños, los niños que no lo saben se les va quedando, es un trabajo duro porque muchos no sabemos dibujar, otros pues se nos dificulta escribir, pero pues nos ayudamos y así vamos saliendo".

Uno de los aspectos fundamentales en la elaboración del paisaje es que el lenguaje plasmado en las tablas ha sido legitimado socialmente por sus hablantes, porque quieren darle vida a la lengua que les trasmitieron sus padres y abuelos. 
Imagen 1. Paisaje lingüístico en náhuatl, 30 de noviembre de 2019, Santa Ana Tlacotenco.

Foto de Elsa Del Valle Núñez.

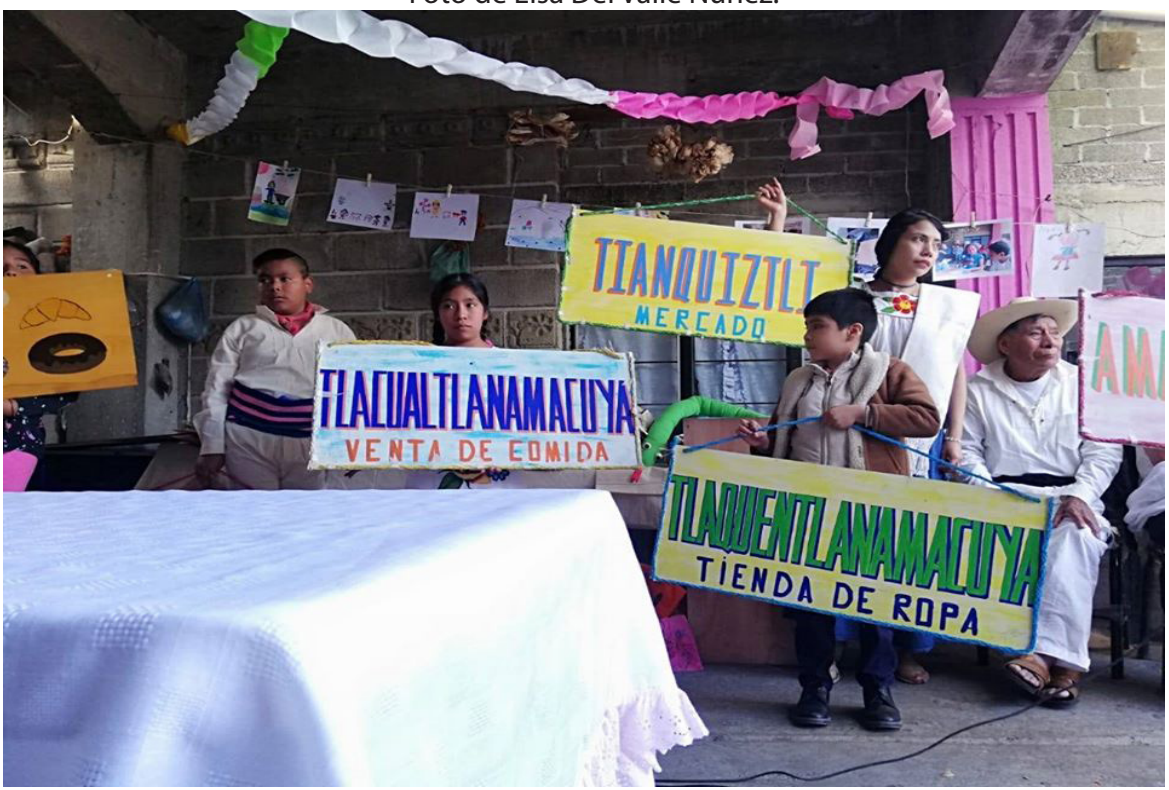

\section{Conclusiones}

El paisaje lingüístico es una estrategia de revitalización para la lengua náhuatl en Santa Ana Tlacotenco. Es efectiva toda vez que hay una comunidad de hablantes que saben leer y escribir en la lengua originaria y otra comunidad de niños y jóvenes que están aprendiendo náhuatl en este pueblo originario. Por lo que, el paisaje lingüístico en lengua náhuatl es un bien cultural producido por sus hablantes y por una sociedad de consumo que es hablante de esta lengua y por otra, que aunque no lo es, valora la diversidad lingüística.

El paisaje lingüístico es un derecho indígena de los pueblos y las comunidades originarias. Los gobiernos deben dar cabida a que sus agendas contemplen la implementación de políticas lingüísticas cuyo objetivo sea la colocación de anuncios en lenguas originarias elaborados por los propios hablantes, según los principios de territorialidad.

Para coadyuvar a la elaboración de paisajes lingüísticos, las iniciativas privadas como empresas y comercios deberían celebrar contratos de colaboración para difundir y promover el uso de las lenguas en el mercado regional y nacional. 


\section{Referencias}

BAKER, C. (1993). Fundamentos de educación bilingüe y bilingüismo. Madrid, España: Cátedra.

CÓRDOVA, L. y YATACO,M. (2019). Paisajes en lenguas indígenas latinoamericanas:r epresentaciones, reivindicaciones y consumo. Signo y seña, pp. 89-106.

Constitución Política de los Estados Unidos Mexicanos, 2020

FLORES, J y CÓRDOVA, M. (2012). Guía de revitalización lingüística: para una gestión formada e informada.

FISHMAN, J. (1991). Reversing language shift. Theoretical and empirical foundatios of assistance to threatened languages. Multilingual Matters, p. 76. Clevedon: Multilingual Matters.

HINTON, L. (2001). Language Revitalization an Overview. Hinton \& K. H. The green book of language revitalization in practice, pp. 51-59, Berkeley: Academic Press.

INALI, Resumen de actividades 2017. https://site.inali.gob.mx/descargas/ CARPETA_SEGUNDA_SESION_ORDINARIA_2017/6.2\%20RESUMEN\%20DE\%20 ACTIVIDADES.pdf

LANDRY, R y Richard Y. B. (1997). Linguistic landscape and ethnolinguistic vitaly. An empirical study. Journal of language and social psychology, pp. 23-49.

Ley General de Derechos Lingüísticos de los Pueblos indígenas. (2020), México.

LÓPEZ, L. E. (2015). El hogar, la comunidad y la escuela en la revitalización de las lenguas originarias de América Latina. En Pueblos indígenas y educación, pp.205329. Quito Ecuador: Abya-Yala.

SICHRA, I. (2014). No solo la última palabra, sobre todo la primera, Familias revierten el desplazamiento intergeneracional en el área urbana. Encuentro internacional de egresados del PROEIB Andes Cochabamba, pp.1-21.

SICHRA, I. (2016). Políticas lingüísticas en familias indígenas: cuando la realidad supera la imaginación. UniverSOS, pp.135-151.

SILVA, D. (2008). Techahchan huel nelli motemaquixtiz in tonahuatlahtol intla ticnequih macahmo polihui. Nitetlatlalhuiz. Estudios de Cultura Náhuatl, 39, pp.277-285. 